\title{
Uso de drogas e cuidado ofertado na Raps: o que pensa quem usa?
}

\author{
Drug abuse and care offer in the Psychosocial Care Network: what \\ does the user think?
}

Milena Vitor Gama Duarte', Gabriela da Silva Barros', Barbara E. B. Cabral1

DOI: 10.1590/0103-1104202012715

RESUMO O estudo pretendeu compreender como usuários do Centro de Atenção Psicossocial, Álcool e Drogas (Caps AD III) de Petrolina (PE), com experiência de internação em comunidades terapêuticas, avaliam as propostas terapêuticas desses dois tipos de dispositivos. Para tanto, buscou-se conhecer suas experiências de cuidado e analisar as possíveis convergências e divergências quanto às ofertas terapêuticas, valorizando-se seus pontos de vista. Tratando-se de pesquisa qualitativa, com intuito avaliativo, a entrada em campo ocorreu na perspectiva da cartografia, recorrendo-se à ferramenta usuário-guia, com definição de dois interlocutores, além da escrita de diários cartográficos. Os resultados foram circunscritos com respaldo na metodologia de relatos orais, destacando-se cinco eixos interpretativos: 1. compreensões sobre lógica de cuidado na perspectiva de usuários; 2. burocratização e protocolização da produção de cuidado; 3. medicalização nos dispositivos de cuidado; 4. cuidado versus controle; e 5. uso de substâncias psicoativas e questões de gênero. Visando contribuir para a análise do impacto da Política Nacional de Saúde Mental em dispositivos da Rede de Atenção Psicossocial no semiárido nordestino, o estudo visibilizou a importância de processos avaliativos permanentes, com ênfase no protagonismo de usuários/as, apresentando efeitos do processo de Reforma Psiquiátrica na região e caminhos possíveis para seu fortalecimento.

PALAVRAS-CHAVE Serviços de saúde mental. Redução do dano. Pesquisa sobre serviços de saúde. Liberdade.

ABSTRACT The study aimed to comprehend how users of a Psychosocial Care Center - Alcohol and Drugs (Caps AD III) in the city of Petrolina ( $P E)$, also having experienced hospitalization in therapeutic communities, evaluate the therapeutic proposals of the two types of service. Therefore, their care experiences were taken for analysis, valuing their points of view and considering the possible convergences and divergences between the therapeutic offers. It was a qualitative research, with evaluative purpose. The fieldwork occurred from the perspective of cartography, using the user-guide tool, with the definition of two interlocutors. Data analysis was supported by the methodology of oral reports, indicating five interpretative axes: 1. users' comprehension of the care logic; 2. bureaucratic and protocolized production of care; 3. medicalization in care devices; 4 . care versus control practices; and 5. drug abuse and gender issues. In order to contribute to the analysis of the impact of the National Mental Health Policy on devices of the Psychosocial Care Network in the northeastern semiarid, the study showed the importance of permanent evaluation processes, emphasizing the role of users,

1 Universidade Federal do Vale do São Francisco (Univasf) - Petrolina (PE), Brasil.

milenavgduarte@gmail.com presenting effects of the Psychiatric Reform process and possible ways to strengthen it.

KEYWORDS Mental health services. Harm reduction. Health services research. Freedom. 


\section{Introdução}

\section{A questão de pesquisa situada: uso de drogas e política de saúde mental no Brasil}

Por meio de discussões ocorridas na III Conferência Nacional de Saúde Mental, em 2001, foi afirmada a necessidade da criação

de uma rede de serviços de atenção aos usuários de álcool e outras drogas, integrada à rede do Sistema Único de Saúde (SUS), que evite a internação em hospitais psiquiátricos e em clínicas ${ }^{1(60)}$.

Em 2003, o Ministério da Saúde² anunciou a Política para a atenção integral a usuários/ as de álcool e outras drogas, em que se responsabiliza pelo desafio da prevenção, do tratamento e da reabilitação dessas pessoas, compreendendo a temática enquanto uma questão de saúde pública². Mais recentemente, o Decreto $\mathrm{n}^{\circ} 9.761^{3}$, de 2019, que aprova a Política Nacional sobre Drogas, assume a manutenção das pessoas abstinentes em relação ao uso de drogas ${ }^{3}$ como objetivo da assistência, remove o lugar da Redução de Danos (RD) como política oficial e redireciona o foco para as Comunidades Terapêuticas (CT) ${ }^{4}$.

Assim, abandonando quaisquer perspectivas moralizantes, é necessário compreender o conflito histórico entre o paradigma da RD e a política antidrogas, que se sustenta na abstinência. Essa política proibicionista remete a

uma rede de instituições que define uma governabilidade das políticas de drogas e que se exerce de forma coercitiva na medida em que faz da abstinência a única direção de tratamento possível5(157).

No Brasil, a Política Nacional de Saúde Mental (PNSM), forjada no seio do processo de Reforma Psiquiátrica Brasileira (RPB), consolida-se como política de Estado, tendo como principais marcos legais a Lei $\mathrm{n}^{0} 10.216$, de $2001^{6}$, conhecida como Lei Nacional de Reforma Psiquiátrica, e a Portaria n ${ }^{0} 3.088$, de 20117 , que institui a Rede de Atenção Psicossocial (Raps). Em sua implementação, a PNSM incorpora o paradigma de RD.

No entanto, nos últimos tempos, enquanto o número de leitos em hospitais psiquiátricos teve forte queda, as CT cresceram em quantidade $^{8}$ - as quais foram inseridas na Raps via Portaria $\mathrm{n}^{0} 3.088 / 2011^{7}$, no componente de Atenção Residencial de Caráter Transitório. Ofertam cuidados contínuos, por até nove meses, para adultos com necessidades decorrentes do uso de drogas. Os Centros de Atenção Psicossocial (Caps), incluindo a modalidade álcool e drogas III (Caps AD III), são serviços de caráter aberto e comunitário e, no caso do Caps AD III, ofertam serviços de atenção contínua (24 horas), retaguarda clínica e acolhimento noturno a pessoas com intenso sofrimento psíquico decorrente do uso de drogas.

Importa destacar que as mudanças impostas pela Coordenação Nacional de Saúde Mental, por meio da Portaria n ${ }^{0} 3.588 / 2017^{9}$, publicada sem diálogo com movimentos sociais em defesa da RPB em curso, demandam análise aprofundada e permanente. Esta pesquisa, vinculada ao Observatório de Políticas e Cuidado em Saúde do Sertão do Submédio São Francisco, que integra a Rede Nacional de Observatórios de Políticas Públicas em Saúde e Educação em Saúde, busca contribuir para esse necessário debate, aprofundando a compreensão sobre a produção de cuidado a pessoas que fazem uso de substâncias psicoativas, tomando por base os marcos legais destacados - a Lei $\mathrm{n}^{\circ}$ $10.216 / 2001^{6}$ e a Portaria ${ }^{0} 3.088 / 2011^{7}$.

Nesse panorama, o estudo pretendeu compreender como usuários do Caps AD III de Petrolina (PE), com experiência de internação em CT, avaliam as propostas terapêuticas desses dois tipos de dispositivos. Para tanto, buscou-se conhecer suas experiências de cuidado e analisar as possíveis convergências e divergências quanto às ofertas terapêuticas, 
valorizando-se seus pontos de vista. Tal ênfase se justifica pelo reconhecimento de que é aos/ às destinatários/as das ofertas terapêuticas, tomados como atores sociais, que mais interessa uma política de saúde mental que responda às suas necessidades de saúde.

\section{Material e métodos}

\section{O caminho guiado pela questão de pesquisa}

Tratou-se de uma pesquisa de caráter qualitativo ${ }^{10}$, respaldada na perspectiva da inserção cartográfica ${ }^{11}$. No que tange aos/às interlocutores/as da pesquisa, foi utilizada a ferramenta usuário-guia, compreendida como o relato da produção de cuidado com um usuário que percorre os serviços das Redes de Atenção à Saúde - nesse caso, a Raps - para o atendimento às suas necessidades, possuindo as características de um caso que demanda muitas redes de cuidado e a necessidade de reinvenção das intervenções em saúde mental ${ }^{12}$.

A definição de usuários tomados como guia se deu mediante indicação inicial de alguns nomes pela equipe do serviço, cujos prontuários foram posteriormente analisados, para a confirmação dos critérios de inclusão e exclusão, tendo em vista a caracterização de um usuário-guia. Foram também considerados os dias de presença no serviço, de modo a facilitar os encontros. Assim, foram definidos dois usuários, uma mulher e um homem, com idade superior a 18 anos, vínculo institucional de cuidado com Caps AD III de Petrolina (PE) e histórico de internação em CT. A proposta de pesquisa foi apresentada a esses usuários e, a partir de seu aceite em colaborar como interlocutores/as, foram combinados encontros, em que o fio condutor era tecido por suas narrativas.

A ferramenta usuário-guia permite valorizar, sobretudo, os diversos encontros produzidos a partir do acompanhamento dos/ as usuários/as definidos/as: com os/as trabalhadores de saúde, familiares e amigos/as indicados por eles/as, mas, principalmente, a partir das narrativas de si mesmos. Portanto, as fontes que constituíram a matéria-prima desse estudo foram diversas, incluindo, além das narrativas dos/as usuários/as, de seus familiares e amigos/as, indicados/as pelos/as usuários/as, as narrativas dos/as profissionais de saúde, a consulta a prontuários e outros documentos do serviço e escrita de diários cartográficos.

Como indicado, a entrada em campo ocorreu na perspectiva da inserção cartográfica, que privilegia a construção de metas a partir do que vai sendo produzido no percurso"11. Assumiuse, assim, que a produção de compreensões sobre um fenômeno ocorre pelas e nas relações estabelecidas entre pesquisador/a e campo. Assim, foi fundamental recorrer à escrita de diários cartográficos para registro do processo de pesquisa, incluindo notas, observações, fragmentos narrativos, percepções da realidade, sentidos produzidos, inquietações, afecções, enfim, tudo o que brotou e se destacou a partir do que foi vivido em campo.

No contexto da imersão cartográfica, os encontros se respaldaram na metodologia de relatos orais, pela colheita de narrativas ${ }^{13,14}$ por meio de entrevistas individuais abertas, que tiveram o formato de conversas, ocorrendo do modo mais fluido possível, sendo gravadas em áudio, formato $\mathrm{mp} 3$, mediante consentimento dos/as interlocutores/as, com posterior transcrição integral. As narrativas produzidas trouxeram à cena o/a usuário/a em seu trânsito na vida, ao mesmo tempo em que apresentaram questões relacionadas com o processo terapêutico e expressaram os sentidos tecidos na experimentação do cuidado, constituindo uma porção significativa da matéria-prima tomada para análise.

Para o processo interpretativo do que foi colhido, recorreu-se à análise microvetorial - ou multidimensional ${ }^{15}$, compreendendo-se a produção de cuidado enquanto fenômeno complexo, que requer uma abordagem que 
coloque em diálogo os diferentes olhares nela envolvidos. Dessa maneira, propor uma análise vetorial "é procurar captar o agir e intencionalidade destes agentes quando se movem no jogo social desta produção"15(5), partindo da compreensão de que as ações de cada agente terão repercussões nos demais agentes do sistema, sejam gestores/as, trabalhadores/as e/ou usuários/as.

Nesta pesquisa, foram desenvolvidas atividades relativas ao vetor que se refere ao impacto das normas nas trajetórias existenciais dos usuários, estando em destaque, no caso, a Lei $\mathrm{n}^{0} 10.216 / 2001^{6}$ e a Portaria $\mathrm{n}^{\mathrm{o}}$ $3.088 / 2011^{7}$. Partiu-se do pressuposto de que, a partir das leis e dos respectivos direitos e deveres por elas propostos, as trajetórias em busca de cuidado de usuários/as com necessidades decorrentes do uso de crack, álcool e outras drogas serão agilizadas, melhoradas e simplificadas ${ }^{\mathbf{1 5}}$; contudo, efeitos contrários ao desejado também podem ser produzidos.

A metodologia de relatos orais também respaldou tanto a colheita quanto a análise, uma vez que privilegia a compreensão do sentido desvelado nos encontros, articulando experiência e narrativa ${ }^{\mathbf{1 4}}$. No processo de análise do que foi colhido, foram realizadas leituras atentas das transcrições das conversas e dos diários cartográficos. Em um processo artesanal de compreensão do corpus, foram delineados cinco eixos interpretativos, com atenção à correspondência aos objetivos da pesquisa.

Houve um cuidado quanto ao cumprimento dos aspectos éticos, estando o estudo vinculado ao projeto guarda-chuva intitulado 'Observatório de Políticas e Cuidado em Saúde do Sertão do Submédio São Francisco: Análise microvetorial do impacto da Política Nacional de Saúde Mental em Petrolina-PE', aprovado no Comitê de Ética em Pesquisa da Universidade Federal do Vale do São Francisco (CAAE: 67045917.5.0000.5196, parecer: 2.480 .652 ), tendo como parâmetro a Resolução no 466/12, do Conselho Nacional de Saúde (CNS).

\section{Resultados}

\section{Compreensões tecidas nas trilhas de usuários/as tomados como guia}

No que diz respeito aos dois interlocutores do estudo, optou-se pela utilização dos pseudônimos Rebeca e André. Coincidentemente, ao serem perguntados sobre outras pessoas com quem se poderia conversar sobre a história deles, cada um indicou a própria mãe como fonte, além de outro usuário do Caps e um profissional do serviço.

Com 30 anos de idade, Rebeca tem uma filha de 8 anos. Havia sido admitida no Caps em 2016, com queixa relacionada com o uso abusivo de álcool associado à depressão, por meio de um encaminhamento da Unidade de Pronto Atendimento (UPA). Já havia sido acompanhada no Caps II do município.

Rebeca relata que passou por uma internação de três meses em uma CT, da qual saiu mediante fuga. Sua história abrange tentativas de suicídio, passagem pelas ruas e conflitos familiares. Afirmou ter encontrado no serviço um tripé de sustentação: os grupos, o acompanhamento psicológico e a medicação. Entre suas estratégias de cuidado, destaca a escrita de diários, com trechos redigidos no dia a dia em momentos em que se encontrava mobilizada por algum acontecimento. Rebeca relata a importância do processo de pesquisa para ela, como destacado no fragmento narrativo: "muitas vezes eu preciso me sentir como eu tô me sentindo agora, sendo protagonista da minha história".

Já André tem 41 anos de idade e, entre vários afastamentos e readmissões, é usuário do Caps AD III há 11 anos. Em seu prontuário, consta que é de cor parda, de religião evangélica, que experimentou álcool pela primeira vez aos 8 anos de idade e, aos 12, começou a beber nos finais de semana, por 3 dias seguidos. Nos encontros de pesquisa, relata estar afastado da prática religiosa por se sentir julgado. Começou a fazer uso de tabaco aos 13 anos de 
idade, de maconha, aos 15 e, de cocaína, aos 20 anos de idade. Existe o registro de problemas relacionados com o uso abusivo de substâncias, como a separação conjugal e a perda do trabalho - exercia a função de mototaxista. Após esse último fato, resolveu tentar reconstruir a vida em um município do estado de Minas Gerais, onde se envolveu com uma mulher casada e que, anos mais tarde, entrou em contato com ele, informando que havia gerado uma filha do relacionamento deles. André, contudo, afirma ter dúvidas da paternidade da adolescente.

Relata que passou por uma internação de quatro meses em uma CT, da qual saiu após não conseguir se adaptar às regras impostas. À época do estudo, residia com a mãe, e sua maior queixa se referia à ansiedade causada pela ociosidade.

\section{Eixo 1 Compreensões sobre lógica de cuidado na perspectiva de usuários}

Neste primeiro eixo, foram destacadas as compreensões sobre RD e abstinência, na perspectiva dos usuários. No processo de cartografia da produção de cuidado, surge, em comum, nas concepções sobre a RD apresentadas, a associação com a redução do uso, em que lançam mão de diferentes estratégias. André destaca: "Redução de danos é evitar. Quanto menos, melhor. Quanto mais saber usar, uma bebida, por exemplo na ocasião certa, no momento certo". Rebeca indica:

[...] ultimamente eu tenho feito uso, vamos dizer, de duas cervejas, mas só [...] pra me deixar um pouco animada [...] Eu não bebo mais pra me embriagar, pra ficar à margem da sociedade.

Essa conceitualização traduz princípios do paradigma de $\mathrm{RD}$ de modo simples: diminuir o efeito nocivo do consumo de drogas, sendo, portanto, uma ampliação da vida e operando na contramão de práticas instituídas na ordem predominante ${ }^{16}$.

Em relação aos efeitos da RD em seu processo terapêutico, Rebeca ressalta a importância dessas estratégias para a sua inserção social:
[...] é muito importante, porque aí eu começo a voltar à vida social, eu conquisto a confiança das pessoas que tão ao meu lado, família e amigos próximos.

André destaca a RD como algo que potencializa uma relação mais saudável com o uso de substâncias psicoativas, por meio da reflexão sobre o próprio uso, conforme aponta em seu relato: "Porque quando eu entrei aqui, eu usava bastante, e depois vai abrindo mais a nossa mente, com o redutor de danos".

No Caps AD, a RD vai além das estratégias de redução direta do uso da substância, como exemplificado no trecho do diário cartográfico da pesquisadora 1:

- Caps estava recebendo uma roda de capoeira, que entendi que tinha sido puxada pelo redutor de danos, o mesmo que há um tempinho atrás estava levando reflexões sobre justiça social.

Essa proposta se conecta com a proposta de clínica ampliada, uma vez que se reconhecem os limites e fronteiras do campo da saúde, ampliando-se o repertório de intervenção clínica para além de um modelo técnico-assistencial ancorado na biomedicina ${ }^{17}$. Assim, "a ampliação do foco permite atender demandas para além dos problemas relacionados diretamente ao uso de drogas em si mesmo"18(143).

André se refere ao desejo de chegar à abstinência, destacando um interesse de interromper o uso: "Totalmente! [...] é melhor evitar o primeiro gole [...]. Se segurar... pra não cair em recaída". Rameh-de-Albuquerque ${ }^{19}$ ressalta que alguns/as profissionais podem utilizar a RD tendo a abstinência como horizonte e problematiza o uso recorrente no campo do termo "recaída". No que concerne à "recaída", Rebeca define como "enfiar a cara na cachaça mesmo... beber em excesso, beber pra perder o controle do que tá fazendo... pra fazer coisas que em sã consciência você não faz". Ela diferencia isso do uso controlado, que ela associa à estratégia de $\mathrm{RD}$, como aponta no seguinte fragmento: 
[...] no caso do uso controlado... é a questão de eu beber a primeira dose e saber que eu só posso beber três... ou que, em vez de eu beber a cachaça, eu tomar a cerveja; então, assim, isso tá relacionado à redução de danos.

É importante salientar que a recaída pode ser compreendida como "um retorno a beber ou usar outras drogas depois de um período de abstinência, muitas vezes acompanhada de reintegração de sintomas de dependência"20, remetendo à falha. Assim, compreende-se o conceito de "recaída" como inadequado a partir da perspectiva de RD, respaldada nos Direitos Humanos (DH) e no respeito à liberdade das pessoas, defendendo-se um contraponto a essa concepção, em alinhamento à proposta da recursividade ${ }^{19}$ como uma abordagem mais promissora do fenômeno, do ponto de vista terapêutico. Tratar-se-ia do reconhecimento do desafiante processo de lida com um uso prejudicial de substâncias, prenhe de tensões, por estar situado em um dado contexto existencial. Desse modo, valoriza-se um "movimento inerente a todos os seres vivos, impulsionando-os para mudanças em seu próprio sistema ou na interação com outros sistemas"19(22).

Sobre as relações entre os usuários do Caps, aparece um discurso culpabilizador e normativo, exemplificado na fala da mãe de André, que faz uma interpretação moralista acerca da abordagem não proibicionista do Caps: "[...] tem gente que aqui dentro mesmo usa, aqui mesmo, aqui mesmo, aí vem e não fica bom nunca". O fragmento indica uma ideia de 'cura' atrelada à abstinência e à proibição do uso, indo de encontro ao conceito de RD, o qual, apostando na construção de vínculos, não toma o consumo de substâncias como um problema em si²1. A mãe de Rebeca faz uma queixa parecida, relatando que a filha "deu muito trabalho no começo porque se envolvia com o povo daqui, tinha alguém que dava bebida a ela na rua, na hora que saía... e ficava pelas ruas".

Os interlocutores confirmam a existência desses modos de relação entre os usuários do Caps AD III. André, por exemplo, diz que, no serviço, "[...] um bate a abstinência e fica falando para o outro 'vou beber, vou beber, tô com vontade de beber', aí um vai lá e chama o outro". Um amigo de Rebeca, ao ser entrevistado junto, em sua companhia, relata que os dois se conheceram quando "ela trazia muita cachaça aqui pra porta, eu era de uns que bebia junto com ela". Rebeca, descrevendo outro viés para a relação entre os usuários, enfatiza:

é um processo pra reduzir os danos também, e a cada grupo que a gente participa, através de relatos de outras pessoas ou do nosso próprio, a gente faz uma reflexão do que é viável, do que é melhor pra mim.

\section{Eixo 2 Burocratização e protocolização da produção de cuidado}

Este eixo se refere, principalmente, à reprodução de práticas profissionais engessadas no contexto do Caps AD III, que se relaciona a uma espécie de rigidez mecânica, em rota de colisão com o ideário da RPB e distanciada das necessidades concretas de usuários da Raps. $\mathrm{O}$ fragmento narrativo de André sustenta essa compreensão:

Tem uns psicólogos aqui [...] parece que as funções dele é estar com o computador. Quando eu chamo eles pra conversar, eu percebo que eles têm outros afazeres, como quem tá numa pressa pra ouvir, pra me ouvir logo... e ir logo lá pra fazer outros afazeres...

Os serviços de atenção psicossocial precisam garantir que quem os usa seja escutado, relatando suas dificuldades, medos e expectativas. Assim, é de suma importância que vínculos afetivos e profissionais sejam estabelecidos, que usuários/as se percebam escutados/as e cuidados/as e sintam a equipe efetivamente comprometida e atenta aos seus problemas ${ }^{22}$.

Lancettii ${ }^{23}$ discute a centralização do Caps em si como um significativo obstáculo ao 
cuidado, revelando pouca abertura para a dimensão territorial e existencial de usuários/ as. Tal aspecto contribui para um processo de cronificação - do serviço, das práticas, das relações -, obrigando os/as usuários/as a se adaptarem às ofertas rigidamente impostas. Com relação a isso, é importante evidenciar os achados sobre a institucionalização dos/as usuários/as no Caps, conforme o narrado em um dos diários cartográficos da pesquisadora 2, que fez referência ao processo de definição dos interlocutores da pesquisa:

O profissional nos disse que os usuários do Caps nunca deixariam de ser do Caps, o que me levou a reflexões acerca do estigma por trás disso e da ideia de uma dependência crônica do serviço que, ao meu ver, prejudica o desenvolvimento da autonomia.

Rebeca também faz algumas reflexões sobre esse processo:

[...] principalmente por ter pessoas aqui com mais de cinco anos, eu penso que o serviço entende que é terapia pro resto da vida, e não com prazo de validade, com prazo pra terminar.

Outro fragmento narrativo seu reforça o questionamento dos processos de cuidado:

se a gente ficar muito tempo, não é interessante, talvez seja por isso que os governantes não dão credibilidade ao Caps, porque de 100\%, vê melhora em 2\%.

Sobre isso, destaca-se que a aproximação com os/as profissionais de saúde na Estratégia Saúde da Família (ESF), eixo organizador da Atenção Primária à Saúde, poderia apoiar o enfrentamento da cronificação, considerando a sua inserção no território ${ }^{23}$, pela ampliação dos projetos terapêuticos singulares.

\section{Eixo 3 Medicalização nos dispositivos de cuidado}

No que se refere ao uso de medicamentos no contexto da produção de cuidado, as experiências narradas pelos interlocutores revelam aspectos coincidentes, que refletem esta como a principal estratégia terapêutica. André, avaliando a atuação de um profissional do Caps, destaca: “[...] esse médico aí quer só passar remédio forte pra pessoa”. Em outro momento, relata:

Na maioria das vezes, eu interrompo o tratamento justamente por causa disso mesmo... Eu tava tomando uns medicamentos muito fortes, aí eu decidi parar por minha conta própria.

Ao se referir à experiência na CT, André enfatiza novamente o fato de ter diminuído o uso de medicação sem indicação médica: "Por conta própria, sabe? Para eu não ficar muito grogue, para eu não ficar dormindo muito, porque eu tava dormindo e não via nada".

Essas narrativas indicam a importância de refletir sobre o fenômeno da medicalização, que inclui, ao mesmo tempo que transcende, o uso excessivo de medicamentos. Remete à lógica de interpretar problemas complexos, cujas raízes são diversas, como fatos médicos, clínicos e objetivos ${ }^{24}$. Cabe, ainda, atentar a um dado exercício de autonomia, pelo usuário, no uso do medicamento prescrito.

André, ao se referir aos efeitos colaterais dos medicamentos, realça o fato de ficar "grogue":

Grogue pra mim... a pessoa fica fora do real, [...] fica drogado. É a mesma coisa de tá drogado. A mesma coisa não, a pessoa fica drogado, porque deixa de usar uma droga, para tomar outras, que é o medicamento, é uma droga.

Rebeca, ao retomar a vivência na CT, aproxima-se dessa perspectiva, ao relatar: "[...] lá no centro de recuperação não era possível fazer uso, só que a gente... a gente fazia uso de coisas piores, que era as medicações".

A cartilha intitulada "Tratamento da Dependência Química: Conceitos e Abordagens, ${ }^{25}$, proposta pela Confederação Nacional de Municípios, destaca que o fármaco é usado em conjunto com outros tratamentos 
e age sempre em aversão à droga, substituindo os efeitos da substância e tratando os sintomas da abstinência ${ }^{25}$. No âmbito da produção de cuidado em saúde mental, é fundamental considerar a complexidade existencial em que o uso de drogas se insere, sendo o medicamento tão somente um dos vários recursos.

\section{Eixo 4 Cuidado versus Controle}

Em relação ao cotidiano nas $\mathrm{CT}$, os dois usuários destacam a relação com as regras do serviço, enxergadas de maneira negativa, como pode ser exemplificado nos seguintes fragmentos: "Lá é cheio de regra, até demais... Tudo tem que ter regra, mas lá já passa fora... já passa dos limites" (André); e

[... fiquei lá três meses, me revoltando, me entristecendo, me angustiando, sem ter nem a liberdade de falar o que eu queria, o que eu pensasse... cumprindo ordens, seguindo regras. (Rebeca).

Além do destaque às regras, Rebeca ressalta que, na CT, não havia espaços de lazer: "[...] nós éramos obrigados a cumprir as normas e nenhuma delas envolvia lazer". Isso se alinha ao apontado no Relatório da Inspeção Nacional em Comunidades Terapêuticas $^{\mathbf{8}}$, de que os dispositivos vistoriados seguem uma rotina rígida, em que as características, as necessidades e as trajetórias individuais não são consideradas, sendo raras as atividades de lazer e, quando autorizadas, são de cunho religioso.

$\mathrm{O}$ aspecto religioso também foi destacado pelos interlocutores, que destacaram que a maioria das atividades ofertadas tinham esse caráter. Sobre isso, André faz uma avaliação positiva: "De manhã a gente fazia oração, de tarde tinha ensinamento bíblico, de noite tinha culto, todo dia, todo dia tinha culto. Já isso aí eu achava bom".

Rebeca também faz referência às atividades de cunho religioso, como no seguinte fragmento narrativo: "[...] lá tinha mais a questão da religião, da pregação do evangelho, de estudar os provérbios, de limpar a casa, era muito chato!". É muito comum que as CT utilizem a evangelização e a conversão religiosa como as principais formas de recuperação e de reabilitação de usuários de drogas, por meio de um modelo de tratamento centrado na oração e na abstinência ${ }^{26}$.

Por outro lado, a partir da divergência nas avaliações do mesmo item pelos interlocutores, cabe uma reflexão sobre a demanda de reconhecimento e respeito a singularidades, inclusive de crenças religiosas e/ou espirituais. Contudo, dado o caráter laico que serviços de atenção à saúde precisam preservar, a oração ou quaisquer atividades de cunho religioso não podem compor uma prescrição terapêutica, podendo se caracterizar como uma indicação de recurso de autocuidado, a partir das referências de cada sujeito, jamais sendo imposto. Destaca-se, curiosamente, a percepção positiva de Rebeca acerca da relação construída com a fé dentro da CT:

[...] sem a religião, sem Deus, não sou nada, então a religião lá influenciou bastante pra que eu frequentasse igreja, pra que eu lesse a Bíblia, porque eu não tinha esse hábito antes. Me ajuda bastante, principalmente no momento de abstinência, de apuros, sentimentos de angústia, aí quando eu vou ler a Bíblia, isso ali me dá uma melhora significativa.

Em relação ao questionamento crítico do uso de fundamentos religiosos nas CT, importa realçar que o embasamento de ofertas terapêuticas em práticas e preceitos religiosos pode se configurar como uma violação de direitos, pois é crucial partir do pressuposto de que as pessoas não necessariamente partilham da crença em tela, de modo que o procedimento pode se caracterizar como doutrinação, e não produção de cuidado. Assim, ressalta-se que

[...] dado que tratamento para transtornos mentais decorrentes do uso de álcool e outras drogas é um processo de cuidado em saúde, as bases que o regem não devem ser religiosas, mas laicas. Devem nortear a atenção à 
saúde o conjunto de práticas e de princípios profissionais que orientam o atendimento na área, especialmente quando se trata de atendimentos referendados ou subsidiados pelo Estado, com recursos públicos ${ }^{8(79)}$.

Comparando o modelo terapêutico ofertado pelos dois tipos de serviços, André enfatiza que, na CT, há um distanciamento do contato com a família: "[...] além de a gente não poder sair, a gente não pode fazer uma ligação". O usuário relata que sentia muita ansiedade quando estava sob essa forma de tratamento e, comparando os dois serviços, parece indicar sua preferência pelo Caps, salientando: "[...] é livre, né? Você tá livre e lá tá preso, é a diferença... você tá fora da sociedade".

Rebeca fala sobre um dos maiores pontos de ancoragem da atenção psicossocial - o cuidado em liberdade:

[...] no caso, a liberdade de expressão que a gente tem, pra mim, é uma forma de lazer, a liberdade de escolha também, eu posso escolher o dia que eu quero vir.

Em sintonia a isso, o $12^{\circ}$ registro em diário cartográfico da pesquisadora 2 cita as palavras do amigo de André sobre o Caps, encerrando com a seguinte frase: "[...] aqui você tem liberdade de sair".

Aposta-se na atenção psicossocial, compreendendo que ela promove integralidade e continuidade do cuidado e produz transformações nas realidades sociais em defesa do cuidado em liberdade, da equidade, do respeito às diferenças, da ampliação da autonomia e da garantia de direitos humanos e de cidadania ${ }^{27}$. Nesse sentido, acredita-se que o conceito de liberdade não pode estar exclusivamente relacionado com o serviço ser aberto ou fechado, mas com o "exercício da libertação das práticas de cuidado, diretamente ligado à relação que se estabelece entre as pessoas"28(100).

\section{Eixo 5 Uso de substâncias psicoativas e questões de gênero}

Este eixo se configurou em função das especificidades do ser mulher nos serviços da Raps, que surgiram na produção narrativa de Rebeca, possibilitando levantar reflexões acerca da existência de possíveis barreiras e de estratégias de cuidado que não consideram as necessidades singulares do gênero feminino.

Com relação à sua entrada no Caps AD III, Rebeca expõe:

[...] quando eu cheguei aqui, eu me senti fora... eu me senti de uma certa forma excluída, porque a maioria dos pacientes são do sexo masculino, são homens.

Além disso, a usuária relata:

[...] quando eu cheguei aqui, eu fiquei com muita vergonha, assim... Será que só eu, mulher, no mundo, que sou problemática? Eu pensei, né? E aí eu fiquei triste, deprimida, assim, pelos cantos, eu só vivia pelos cantos.

O conceito de gênero pode ser compreendido como uma construção sócio-histórica, que constitui as relações sociais baseadas nas diferenças entre homens e mulheres, sustentando-se em símbolos, conceitos normativos e instituições, os quais estabelecem o significado de masculinidade e feminilidade e os papéis sociais aceitáveis ou não para homens e mulheres ${ }^{29}$. A partir dessa perspectiva, a Política Nacional de Atenção Integral à Saúde da Mulher ${ }^{\mathbf{3 0}}$ aponta que "mulheres e homens, em função da organização social das relações de gênero, também estão expostos a padrões distintos de sofrimento, adoecimento e morte"30(13).

Em relação ao uso de substâncias psicoativas, destaca-se que as mulheres que fazem uso de substâncias psicoativas são duplamente estigmatizadas: por fazerem uso de drogas e não se enquadrarem nos papéis estabelecidos pela sociedade ${ }^{31}$. Esse processo de estigmatização 
com que se deparam em suas andanças pela vida pode justificar uma predisposição a uma demora na busca por cuidado assim como ao abandono precoce do tratamento ${ }^{32}$.

Assim, aponta-se a importância de considerar possíveis barreiras na produção de cuidado de mulheres que fazem uso/abuso de substâncias psicoativas ao não se dar relevo à incorporação da perspectiva de gênero no planejamento das ações de saúde nesse contexto.

\section{Conclusões}

\section{Ainda algumas considerações, a título de arremate - do texto, mas não do debate...}

O estudo permitiu uma avaliação das propostas terapêuticas de pontos de atenção da Raps de Petrolina (PE), na perspectiva de quem os usa, produzindo um leque de provocações que permitem - e mesmo indicam a necessidade de - repensar a produção de cuidado, afinando-a a partir da lógica da atenção psicossocial. As narrativas dos/as usuários/as tomados como guia indicaram a demanda de reorganização, singularização e diversificação das estratégias de cuidado, na conexão com uma escuta cuidadosa de quem recorre aos serviços em busca de cuidado.

As compreensões produzidas ressaltam a importância de garantir, efetivamente, não apenas a voz a usuários/as, mas, sobretudo, a consideração do que dizem, como fio condutor na construção de projetos terapêuticos singulares e no delineamento de atividades pertinentes. Evidenciou-se a potência de um serviço aberto e territorial, como o Caps, e dos vínculos construídos com a equipe, considerando a possibilidade de circulação e a liberdade sua marca distintiva e valorizada, em comparação com as CT.

A partir dos resultados, reafirma-se a importância de continuar defendendo o cuidado em and Contributor ID). dos movimentos sociais em curso, que vêm efetivando um processo vivo de transformação dos modos de cuidado em saúde mental no Brasil, incluindo o Movimento de Luta Antimanicomial e de Antiproibicionismo.

O estudo se assume, em sua natureza, como não generalizável; porém, a aposta é de que aponta reflexões pertinentes em torno do cuidado produzido na Raps. Como possibilidades de novos estudos, sugerem-se análises que objetivem compreender o funcionamento dos dispositivos de saúde mental no atendimento a questões específicas de gênero. Outrossim, estudos que busquem compreender possíveis reproduções do modelo manicomial, inclusive na relação com o fenômeno da medicalização em serviços da Raps, podem contribuir para o aprimoramento da produção de cuidado nos territórios.

Cabe ressaltar, por fim, que as compreensões produzidas no estudo se contrapõem à Nota Técnica $n^{0} 11 / 2019^{33}$, publicada, no início do ano de 2019, pela Coordenação-Geral de Saúde Mental, Álcool e Outras Drogas, do Ministério da Saúde; e à Política Nacional sobre Drogas (Decreto $\mathrm{n}^{0}$ 9.761, de 2019)3 , que incentiva um retorno à lógica manicomial, como a diretriz de expansão das CT. É imperativo reconhecer que algumas das CT se configuram como os manicômios da atualidade, tensão com que atores da $\mathrm{RPB}$ precisam se relacionar.

\section{Colaboradoras}

As autoras tiveram tarefas distintas: Cabral BEB (0000-0002-7941-5633)* contribuiu para elaboração do manuscrito com as seguintes atividades: concepção e planejamento do estudo e revisão crítica do seu conteúdo. As demais autoras, Duarte MVG (0000-0003-2476194X)* e Barros GS (0000-0002-4957-2793)*, colaboraram igualmente para concepção, planejamento, análise e interpretação dos dados, para elaboração do rascunho e para revisão crítica do conteúdo e aprovação da versão final do manuscrito. 


\section{Referências}

1. Brasil. Ministério da Saúde. Conselho Nacional de Saúde. Relatório Final da III Conferência Nacional de Saúde Mental; 11-15 dez. 2001; Brasília, DF: Ministério da Saúde; 2002.

2. Brasil. Ministério da Saúde. A Política do Ministério da Saúde para atenção integral a usuários de álcool e outras drogas. Brasília, DF: Ministério da Saúde; 2003.60 p.

3. Brasil. Decreto $n^{\circ}$ 9.761, de 11 de abril de 2019. Aprova a Política Nacional sobre Drogas. Diário Oficial da União [internet]. 12 Abr 2019. [acesso em 2019 fev 3]. Disponível em: http://www.planalto.gov.br/ccivil_03/_ato2019-2022/2019/decreto/D9761.htm.

4. Conceição TFF, Pereira MO. Todo camburão tem um pouco de navio negreiro: uma análise sobre criminalização de substâncias psicoativas e o encarceramento de mulheres negras. In: Pereira MO, Passos RG, organizadores. Luta antimanicomial e feminismos: inquietações e resistências. Rio de Janeiro: Autografia; 2019. p. 111-140.

5. Passos EH, Souza TP. Redução de danos e saúde pública construções alternativas à política global de "guerra às drogas". Psicol. soc. (Online) [internet]. 2011 [acesso em 2019 fev 3]; 23(1):154-162. Disponível em: http://www.scielo.br/pdf/psoc/ v23n1/a17v23n1.pdf.

6. Brasil. Lei n ${ }^{\circ} 10.216$, de 6 de abril de 2001. Dispõe sobre a proteção e os direitos das pessoas portadoras de transtornos mentais e redireciona o modelo assistencial em saúde mental. Diário Oficial da União [internet]. 7 Abr 2001. [acesso em 2020 jun 23]. Disponível em: http://www.planalto.gov.br/ccivil_03/leis/leis_2001/110216.htm\#: :text=LEI\%20 No\%2010.216\%2C\%20DE,modelo\%20assistencial\%20em\%20sa\%C3\%BAde\%20mental.

7. Brasil. Ministério da Saúde. Portaria no 3.088 , de 23 de dezembro de 2011. Institui a Rede de Atenção Psicossocial para pessoas com sofrimento ou transtorno mental e com necessidades decorrentes do uso de crack, álcool e outras drogas, no âmbito do SUS. Diário Oficial da União [internet]. 24 Dez 2011. [acesso em 2018 dez 20]. Disponível em: bvsms.saude.gov.br/bvs/saudelegis/gm/2011/ prt3088_23_12_2011_rep.html.

8. Conselho Federal de Psicologia. Relatório da Inspeção Nacional em Comunidades Terapêuticas. Brasília, DF: CFP; 2018. 169 p.

9. Brasil. Ministério da Saúde. Portaria n ${ }^{0} 3.588$, de 21 de dezembro de 2017. Altera as Portarias de Consolidação $n^{0} 3$ e $n^{0} 6$, de 28 de setembro de 2017 , para dispor sobre a Rede de Atenção Psicossocial, e dá outras providências. Diário Oficial da União [internet]. 22 Dez 2017. [acesso em 2018 dez 20]. Disponível em: http://bvsms.saude.gov.br/bvs/ saudelegis/gm/2017/prt3588_22_12_2017.html.

10. Minayo MCS. Ciência, técnica e arte: o desafio da pesquisa social. In: Minayo MCS, organizadora. Pesquisa social: teoria, método e criatividade. Petrópolis: Vozes; 1994. p. 9-30.

11. Passos E, Barros RB. Cartografia como método de pesquisa-intervenção. In: Passos E, Kastrup V, Escóssia L, organizadores. Pistas do método da cartografia: Pesquisa-intervenção e produção de subjetividade. Porto Alegre: Sulina; 2015. p. 17-31.

12. Abrahão AL, Merhy EE, Gomes MPC, et al. O pesquisador in-mundo e o processo de produção de outras formas de investigação em saúde. In: Gomes MPC, Merhy EE, organizadores. Pesquisador In-Mundo: um estudo da produção do acesso e barreira em saúde mental. Porto Alegre: Rede Unida; 2014. p. 155-170.

13. Benjamin W. O narrador: considerações sobre a obra de Nikolai Leskov. In: Benjamin W. Magia e técnica, arte e política: ensaios sobre literatura e história da cultura. 7. ed. São Paulo: Brasiliense, Obras escolhidas; 1996. p. 197-221. 
14. Cabral BEB, Morato HTP. A questão de pesquisa como bússola: notas sobre o processo de produção de conhecimento em uma perspectiva fenomenológica existencial. In: Barreto CLBT, Morato HTP, Caldas MT. Prática psicológica na perspectiva fenomenológica. Curitiba: Juruá; 2013. p. 159-181.

15. Merhy EE. Criação de Observatório Microvetorial de Políticas Públicas em Saúde e Educação em Saúde. Rio de Janeiro: UFRJ; 2013.

16. Lancetti A. Clínica peripatética. 10. ed. São Paulo: Hucitec; 2016.

17. Brasil. Ministério da Saúde, Secretaria Executiva, Núcleo Técnico da Política Nacional de Humanização. Humaniza SUS: a clínica ampliada. Brasília: Ministério da Saúde; 2004. 17 p.

18. Petuco DRS. Redução de Danos: das técnicas à ética do cuidado. In: Ramminger T, Silva M, organizadores. Mais substâncias para o trabalho em saúde com usuários de drogas. Porto Alegre: Rede Unida; 2014. p. 133-148.

19. Rameh-de-Albuquerque RC. Da pessoa que recai à pessoa que se levanta: a recursividade dos que usam crack [tese]. São Paulo: Universidade Federal de São Paulo; 2017.

20. World Health Organization. Lexicon of alcohol and drug terms [internet]. Geneve: WHO; 2015. [acesso em 2018 jul 15]. Disponível em: http:// www.who.int/substance_abuse/terminology/lexicon_alcohol_drugs_spanish.pdf?ua=1.

21. Torres MRS, Vidal PEV. Redução de danos e psicanálise de orientação lacaniana nas internações de usuários de drogas. Ecos, Estud. Contemp. Subj [internet]. 2016 [acesso em 2019 fev 6]; 7(1):59-67. Disponível em: http://www.periodicoshumanas. uff.br/ecos/article/view/1835/1423.

22. Amarante P. Saúde Mental e atenção psicossocial. Rio de Janeiro: Fiocruz; 2007.
23. Lancetti A. Contrafissura e plasticidade psíquica. São Paulo: Hucitec, 2015.

24. Toassa G. Sociedade tarja preta: uma crítica à medicalização de crianças e adolescentes. Fractal rev. psicol. [internet]. 2012 [acesso em $2019 \mathrm{fev}$ 06]; 24(2):429-434. Disponível em: http://www.scielo.br/pdf/fractal/v24n2/a15v24n2.pdf.

25. Confederação Nacional de Municípios. Tratamento da dependência química: conceitos e abordagens. Brasília: CNM; 2015.

26. Ribeiro FML, Minayo MCS. As Comunidades Terapêuticas religiosas na recuperação de dependentes de drogas: o caso de Manguinhos, RJ, Brasil. Interface (Botucatu, Online). [internet]. 2015 [acesso em 2019 fev 5]; 19(54):515-526. Disponível em: http://www.scielo.br/pdf/icse/v19n54/1807-5762-icse-19-54-0515.pdf.

27. Brasil. Ministério da Saúde. Saúde Mental no SUS: Cuidado em Liberdade, Defesa de Direitos e Rede de Atenção Psicossocial. Relatório de Gestão 20112015. Brasília, DF: Ministério da Saúde; 2016.

28. Guimarães ACA, Veras AB, Carli AD. Cuidado em Liberdade, um Encontro Entre Paulo Freire e a Reforma Psiquiátrica. Rev. Psicol. Saúde. [internet]. 2018 [acesso em $2019 \mathrm{fev}$ 10]; 10(1):91-103. Disponível em: http://pepsic.bvsalud.org/pdf/rpsaude/ v10n1/v10n1a07.pdf.

29. Scott J. Gênero: uma categoria útil para a análise histórica. Educ. Real. 1995; 20(2):71-99.

30. Brasil. Ministério da Saúde, Secretaria de Atenção à Saúde, Departamento de Ações Programáticas Estratégicas. Política nacional de atenção integral à saúde da mulher: princípios e diretrizes. Brasília, DF: Ministério da Saúde, 2004.

31. Oliveira JF, Paiva MS, Valente CLM. Representações sociais de profissionais de saúde sobre o consumo de drogas: um olhar numa perspectiva de gênero. Ciênc. Saúde Colet. 2006; 11(2):473-481. 
32. Elbreder MF, Laranjeira R, Siqueira MM, et al. Perfil de mulheres usuárias de álcool em ambulatório especializado em dependência química. J. bras. psiquiatr. 2008; 57(1):9-15.

33. Brasil. Ministério da Saúde. Nota Técnica ${ }^{\circ}$ 11/2019. Esclarecimentos sobre as mudanças na PNSM e nas Diretrizes da Política Nacional sobre Drogas. Diário Oficial da União [inter- net]. 5 Fev 2019. [acesso em 2019 fev 10]. Dis-

ponível em: https://pbpd.org.br/wp-content/

uploads/2019/02/0656ad6e.pdf.

Recebido em 05/03/2020

Aprovado em 20/07/2020

Conflito de interesses: inexistente

Suporte financeiro: Universidade Federal do Vale do São

Francisco 